\title{
The Efficacy and Safety of Low Dose versus Usual Dose of Hyoscine During Endoscopic Retrograde Cholangiopancreatography: A Randomized Clinical Trial
}

This article was published in the following Dove Press journal:

Clinical Pharmacology: Advances and Applications

\author{
Hassan Salmanroghani' \\ Massoud Mirvakili (D) \\ Mahtabalsadat Mirjalili $\mathbb{D}^{2}$ \\ Mahmud Baghbanian' \\ Roham Salmanroghani ${ }^{3}$ \\ 'Department of Internal Medicine, Shahid \\ Sadoughi University of Medical Sciences, \\ Yazd, Iran; ${ }^{2}$ Department of Clinical \\ Pharmacy, School of Pharmacy, Shiraz \\ University of Medical Sciences, Shiraz, \\ Iran; ${ }^{3}$ Medical Student Research Center, \\ Tehran University of Medical Sciences, \\ Tehran, Iran
}

Purpose: To evaluate the efficacy and safety of low dose versus usual dose of Hyoscine during endoscopic retrograde cholangiopancreatography (ERCP).

Patients and Methods: This randomized, open-label clinical trial included 282 patients undergoing ERCP who had duodenal peristalsis interfering with cannulation. Patients were randomly divided into two groups: Group one and two received low (5 $\mathrm{mg}$ ) and usual $(10 \mathrm{mg})$ dose of Hyoscine, respectively. Cardiovascular service consultation was performed for all patients before entering the study and performing ERCP. Hyoscine was injected intravenously, and the spasmolytic effect of the drug was assessed while the papilla was in a completely enface view. The time interval between cessation of peristalsis and its further onset was recorded by the chronometer. Also, patient's heart rate and blood pressure were monitored during ERCP by digital monitoring.

Results: The results showed no statistically significant differences in the mean duration of peristalsis, the duration of the antispasmodic activity and the time required to increase the heart rate between two groups $(\mathrm{P}=0.38, \mathrm{P}=0.48, \mathrm{P}=0.32$, respectively). No significant differences were observed regarding the average of heart rate and mean arterial blood pressure (MAP) before drug administration between the two groups ( $\mathrm{P}=0.182$ and $\mathrm{P}=0.29$, respectively), but after the drug administration, tachycardia and hypotension were significantly higher in the second group ( $\mathrm{P}=0.007$ and $\mathrm{P}=0.001$, respectively). There was no statistically significant difference in the frequency of arrhythmia between two groups $(\mathrm{P}=0.08)$. The results also showed that tachycardia and hypotension occurred more frequently in men and elderly patients $(\mathrm{P}<0.05)$.

Conclusion: A low dose of Hyoscine is as effective as the usual dose and its side effects such as alteration in blood pressure and heart rate are much fewer, especially in men and elderly patients.

Keywords: hyoscine, ERCP, peristalsis, spasmolytic effect, cardiovascular abnormalities

\section{Introduction}

Endoscopic retrograde cholangiopancreatography (ERCP) is a technique that uses a combination of luminal endoscopy and fluoroscopic imaging to diagnose and treat conditions associated with the pancreatobiliary system. The endoscopic portion of the examination uses a side-viewing duodenoscope that is passed through the esophagus and stomach and into the second portion of the duodenum. It is normally used for treatment of biliary and pancreatic disorders, such as stone disease, ampulla of Vater/
Correspondence: Hassan Salmanroghan Shahid Sadoughi Hospital, Yazd, Iran Tel +983538224000

Fax +983538224100

Email salmanroghani@hotmail.com
Clinical Pharmacology: Advances and Applications 2020:12 123-130 
papillary abnormalities, and biliary or pancreatic ductal malignancy. Duodenal Peristalsis can decrease the details of anatomical view of the ampulla of Vater and intraduodenal segment of the common bile duct, then absence of peristalsis is necessary during cannulation of biliary and pancreatic ducts. $^{1-3}$

Over the past, glucagon and Hyoscine-N-butyl bromide were used to eliminate the duodenal peristalsis. ${ }^{4-6}$ Glucagon was not used routinely because it is expensive and has side effects such as hypoglycemia and nausea/vomiting, however, its cardiovascular side effects are low. ${ }^{7-9}$ Pharmacologic studies have revealed that Hyoscine-N-butyl bromide is an anticholinergic drug with high affinity for muscarinic receptors located on the smooth muscle cells of the gastrointestinal (GI) tract. Its anticholinergic action exerts a smooth-muscle relaxing/spasmolytic effect. Blockade of the muscarinic receptors in the GI tract is the basis for its use in the treatment of abdominal pain secondary to cramping and for spasmolytic effect during ERCP. Hyoscine also binds to nicotinic receptors, which induces a ganglion-blocking effect. These effects on the cardiovascular system cause untoward effects such as cardiac arrhythmia and fluctuation in blood pressure. ${ }^{10}$

Some studies have indicated that cardiovascular complications, such as hypotension, arrhythmia, and tachycardia, increase with a massive dose of Hyoscine $(\geq 40 \mathrm{mg}){ }^{11}$ This is especially important when it comes to situations like difficult ERCP, in which second and even third dose of Hyoscine may be required. On the other hand, most patients requiring ERCP are elderly and more susceptible to cardiovascular complications. ${ }^{12-15}$ Also, it has been shown that the mean procedure time was longer, and a second ERCP was more common in this population. ${ }^{16}$ Considering the mentioned facts, it is necessary to evaluate the minimum effective dose of this drug.

The aim of this study was to evaluate the effect of low dose ( $5 \mathrm{mg}$ ) of Hyoscine versus usual dose on anti-motility response and cardiovascular outcomes (heart rate and rhythm, blood pressure) of the patients during ERCP.

\section{Patients and Methods}

\section{Patient Population}

This was a prospective, randomized, open-label clinical trial study conducted at Shahid Sadoughi University (SSU) of Medical Center, a tertiary care hospital located in Yazd, Iran. Criteria for inclusion in this study were as follows: patient's informed consent, no evidence of contraindication for Hyoscine use, such as hypersensitivity to drug and known case of myasthenia gravis, over 18 years of age, presence of a disease which needs cholangiopancreatography, duodenal peristalsis during ERCP interfering with cannulation, and anesthesiologist permission to perform anesthesia. The exclusion criteria included patient's dissatisfaction, history of specific cardiovascular diseases (heart failure, myocardial infarction, grade II and grade III of heart block), presence of acute pancreatitis or acute cholangitis before ERCP, severe hypotension (SBP $<100$ ), pregnant or lactating women, and a history of hypersensitivity to Hyoscine (Figure 1).

\section{Ethical Considerations}

This study was approved by the Ethics Committee of Shahid Sadoughi University of Medical Sciences, Yazd, Iran and registered with the protocol number "Ir.ssu.medicine.rec.1396.26" on March 12, 2018. Participants were provided written informed consent and were included in the study after they were provided information on treatment methods. This trial was also registered in Iranian Clinical Trial Registry (IRCT20180421039368N1) and was conducted in accordance with the Declaration of Helsinki.

\section{Intervention}

Patients were enrolled between July 10, 2018, to October 15, 2019. Written consent was obtained from all eligible participants before entering the study. Cardiovascular service consultation was performed for all patients before entering the study and the absence of cardiovascular complications was confirmed. Also, anesthesia consultation was performed for all patients before ERCP. After an anesthesiologist's approval, participants were injected with midazolam or propofol for sedation. The ERCP was performed in a standard fashion with the patient in the prone position, with an Olympus side-viewing video duodenoscopy (Olympus Optical Co, Ltd, Tokyo, Japan). All the procedures were done by expert endoscopist with more than 10 years' experience with ERCP procedure. In our center, deep cannulation of common bile duct is possible in $98 \%$ of patients with precut sphincterotomy and using rotatable papillotome. RAMSAY Sedation Scale was used to determine the degree of anesthesia. All the patients' Ramsay Sedation Score were 4 and 5, meaning that the patients did not have full consciousness and would not be affected by environmental stress conditions. $^{17}$ 


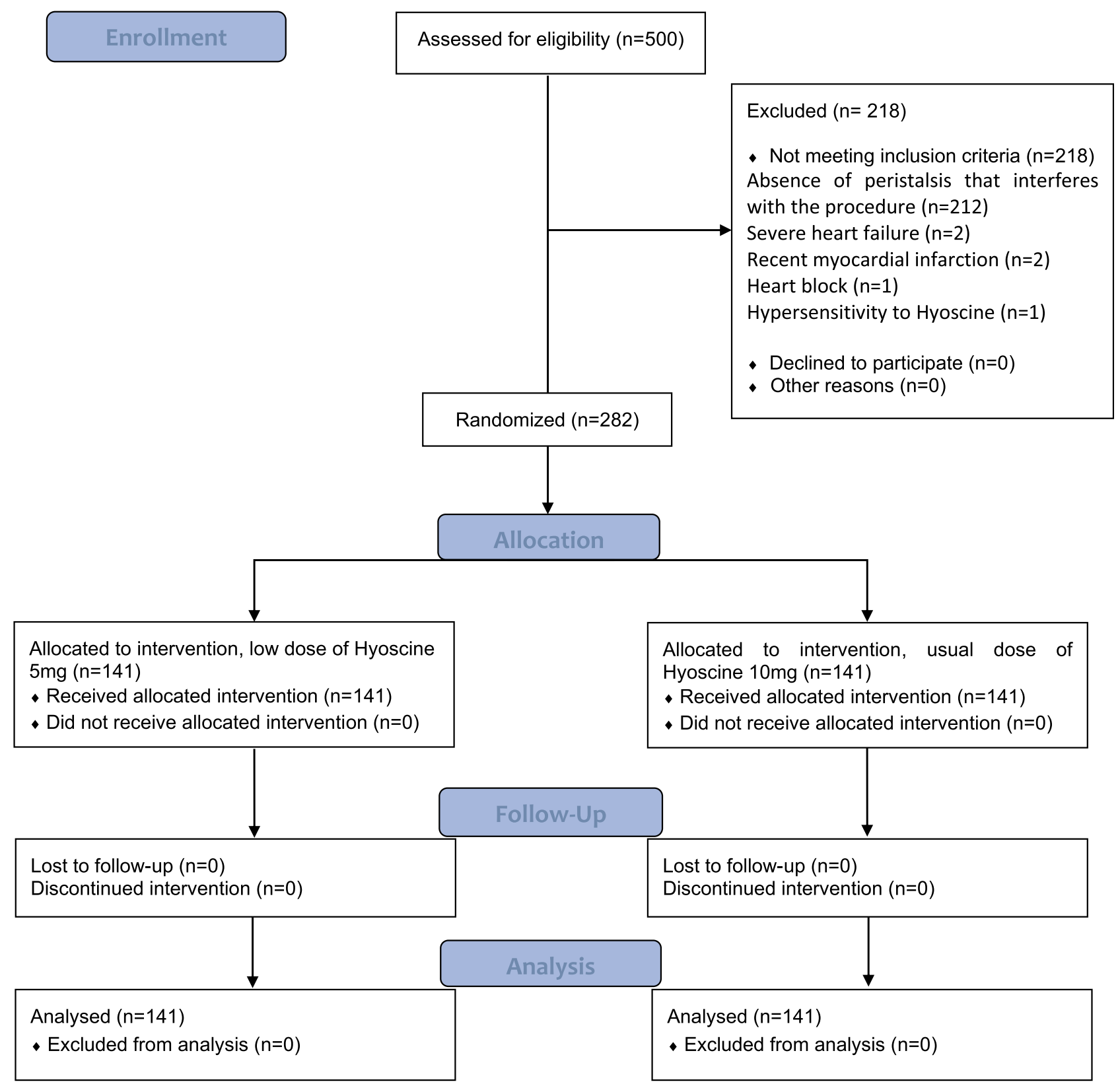

Figure I The flow diagram of the study.

\section{Outcomes (Primary and Secondary)}

A two-part questionnaire was used for data collection. The first part included demographic information (age, sex, and history of underlying diseases), and the second part included clinical information during the procedure. This information included the time interval between injection of the drug and cessation of peristalsis, time to arrest peristalsis, and the time when peristalsis was restarted. Subjects were randomly divided into two groups, group 1 (5 mg Hyoscine) and group 2 (10 mg Hyoscine). The drug was injected intravenously, while the papilla was in a completely enface view, and the spasmolytic effect of the drug was assessed, as the primary outcome. The time interval between the cessation of peristalsis and its further onset was recorded by the chronometer. Also, the patient's heart rate and blood pressure were monitored during the procedure by digital monitoring, as the secondary outcome.

\section{Sampling and Blinding}

The sample size for the trial was calculated based on the following assumptions. The average rate of Hyoscine 
Table I Baseline Characteristics of Patients Randomized in Two Groups

\begin{tabular}{|c|c|c|c|c|}
\hline \multicolumn{2}{|c|}{ Variables } & $\begin{array}{l}\text { Group I } \\
(5 \mathrm{mg})\end{array}$ & $\begin{array}{l}\text { Group } 2 \\
(10 \mathrm{mg})\end{array}$ & P-value \\
\hline \multicolumn{2}{|c|}{ Number of subjects } & 141 & $14 \mid$ & - \\
\hline \multicolumn{2}{|c|}{ Age (mean $\pm S D$ ) } & $54.45 \pm 19.06$ & $53.62 \pm 18.83$ & $0.7 I^{*}$ \\
\hline \multirow[t]{2}{*}{ Gender } & Male, N (\%) & 67 & 65 & \multirow[t]{2}{*}{$0.43^{* *}$} \\
\hline & $\begin{array}{l}\text { Female, } \\
\mathrm{N}(\%)\end{array}$ & 74 & 76 & \\
\hline \multicolumn{2}{|c|}{$\begin{array}{l}\text { Ischemic heart disease, } \\
N(\%)\end{array}$} & 31 & 25 & $0.82 * *$ \\
\hline \multicolumn{2}{|c|}{ Hypertension, $\mathrm{N}(\%)$} & 30 & 43 & $0.76 * *$ \\
\hline
\end{tabular}

Notes: *Independent sample $t$-test, **Pearson chi square test.

cardiovascular side effects, such as tachycardia during ERCP was $32 \%$ in previous studies. ${ }^{18}$ Also, our pilot study showed that the antimotility response with $5 \mathrm{mg}$ Hyoscine was nearly $100 \%$ Hyoscine. Considering all the above, and considering the confidence interval of $95 \%$, power of $80 \%$ and a $10 \%$ reduction in side effects, 282 patients (141 subjects in each group) were enrolled in the study.

\section{Statistical Analysis}

The data were analyzed statistically by SPSS software version 20. For descriptive statistics, the Mean \pm SD index was used for quantitative variables with normal distribution, and the Median \pm Interquartile range was used for quantitative variables without normal distribution. Chi-Square, $T$-test (if the distribution of data was normal), and Mann-Whitney (if the distribution of data was not normal) were used for analysis. $\mathrm{P}<0.05$ was considered as the significance level of tests.

\section{Results}

In this study, 500 patients with biliary tract disease, who were candidates for ERCP, were referred to Shahid Sadoughi Hospital. Of these 500 patients, 218 patients were excluded from the study due to absence of peristalsis that interferes with the procedure $(n=212)$, severe heart failure $(\mathrm{n}=2)$, as well as history of recent myocardial infarction $(n=2)$, heart block $(n=1)$, and hypersensitivity to Hyoscine $(\mathrm{n}=1)$. Finally, 282 ones (141 patients in each group) completed the study. The study flow diagram of patients recruited in this clinical trial study is shown in Figure 1. The mean \pm SD age of patients was $54.03 \pm 18.94$ years. Of the enrolled patients, 151 (53\%) were female, and 132 (47\%) were male. As presented in Table 1, 56 patients (19.9\%) had IHD, and 73 ones (25.9\%) had HTN. There were no significant differences regarding demographic and clinical data between two groups at the baseline (Table 1).

The distribution of people with IHD and HTN according to their gender is summarized in Table 2. Results showed that there was a statistically significant association between IHD and gender $(\mathrm{P}=0.03)$, but there was no significant difference among genders with respect to HTN $(\mathrm{P}=0.71)$. To evaluate the efficacy and safety of the drug, three variables were studied: the time interval between injection of the drug and cessation of peristalsis, the duration of antispasmodic effect, and the time required to increase heart rate. The results of this study showed that there were no statistically significant differences regarding these three variables between two groups. ( $\mathrm{P}=0.48,0.38$, and 0.32 , respectively) (Table 3 ). For evaluating the side effects of the drug, arrhythmia, heart rate, and mean arterial blood pressure (MAP) were studied. The results showed that there was no statistically significant difference in the incidence of arrhythmia between two groups $(\mathrm{P}=0.08)$. The heart rate and MAP were measured for both groups before and after drug administration. The results showed that there was no significant difference regarding mean heart rate before drug administration between two groups $(\mathrm{P}=0.182)$, but after the drug administration, this difference was statistically significant $(\mathrm{P}=0.007)$ (Table 4). Also, MAP was not significantly different between two groups $(\mathrm{P}=0.29)$ before drug

Table 2 The Frequency of Patients with Ischemic Heart Disease and Hypertension by Gender

\begin{tabular}{|c|c|c|c|c|c|c|c|c|c|}
\hline \multicolumn{2}{|c|}{ Variables } & \multicolumn{2}{|c|}{ Ischemic Heart Disease } & \multirow[t]{2}{*}{ Total } & \multirow[t]{2}{*}{ P-value } & \multicolumn{2}{|c|}{ Hypertension } & \multirow[t]{2}{*}{ Total } & \multirow[t]{2}{*}{ P-value } \\
\hline & & Yes & No & & & Yes & No & & \\
\hline \multirow[t]{2}{*}{ Gender } & Male, N (\%) & 31 (25.6\%) & 90 (74.4\%) & $121(100 \%)$ & \multirow[t]{3}{*}{0.03} & $30(24.8 \%)$ & 91 (75.2\%) & $121(100 \%)$ & \multirow[t]{3}{*}{0.71} \\
\hline & Female, $\mathrm{N}(\%)$ & 25 (I5.5\%) & $136(84.5 \%)$ & $161(100 \%)$ & & $43(26.7 \%)$ & II 8 (73.30\%) & $161(100 \%)$ & \\
\hline Total & $56(19.9 \%)$ & $226(80.1 \%)$ & $282(100 \%)$ & & & 73 (25.9\%) & 209 (74.1\%) & $282(100 \%)$ & \\
\hline
\end{tabular}


Table 3 The Comparison Between Efficacy of Low Dose Vs Usual Dose of Hyoscine

\begin{tabular}{|l|l|l|l|}
\hline Variables & Group I (5 mg) & Group 2 (10 mg) & P-value \\
\hline Time required to decrease peristalsis (Mean I SD) & $29.02 \pm 10.65$ & $29.93 \pm 10.94$ & $0.48^{*}$ \\
Duration of antispasmodic effect (Median, Interquartile) & $10(11 \%)$ & $10(10 \%)$ & $0.38^{* *}$ \\
Time required to increase heart rate (Median, Interquartile) & $35(34 \%)$ & $25(48 \%)$ & $0.32^{* *}$ \\
\hline
\end{tabular}

Notes: *Student's t-test, **Mann-Whitney test.

Table 4 The Frequency of Side Effects of Drug by Groups

\begin{tabular}{|c|c|c|c|c|}
\hline \multicolumn{2}{|l|}{ Variables } & \multirow{2}{*}{$\begin{array}{l}\text { Group I (5 mg) } \\
14 \mid(100 \%) \\
0(0 \%)\end{array}$} & \multirow{2}{*}{$\begin{array}{l}\text { Group } 2 \text { (10 mg) } \\
138(97.9 \%) \\
3(2.1 \%)\end{array}$} & \multirow{2}{*}{$\begin{array}{l}\text { P-value } \\
0.08^{*}\end{array}$} \\
\hline Arrhythmia (N, \%) & $\begin{array}{l}\text { No } \\
\text { Yes }\end{array}$ & & & \\
\hline Heart rate & Before drug injection & $89.33 \pm 11.60$ & $88.86 \pm 8.29$ & $0.182 * *$ \\
\hline$($ Mean \pm SD) & After drug injection & $92.72 \pm 11.18$ & $96.32 \pm 10.97$ & $0.007 * *$ \\
\hline Mean arterial blood pressure & Before drug injection & $96.92 \pm 11.42$ & $98.19 \pm 8.71$ & $0.29 * *$ \\
\hline$($ Mean $\pm S D)$ & After drug injection & $93.65 \pm 10.37$ & $89.77 \pm 8.03$ & $0.00 I^{* *}$ \\
\hline
\end{tabular}

Notes: *Chi square test, **Student's t-test.

Table 5 The Frequency of Side Effects of Drug by Age

\begin{tabular}{|c|c|c|c|c|c|}
\hline \multicolumn{3}{|l|}{ Variables } & \multirow{2}{*}{$\begin{array}{l}\text { Group I (5 mg) } \\
91.88 \pm 12.55\end{array}$} & \multirow{2}{*}{$\begin{array}{l}\text { Group } 2 \text { (10 mg) } \\
93.88 \pm 5.90\end{array}$} & \multirow{2}{*}{$\begin{array}{l}\text { P-value* } \\
0.24\end{array}$} \\
\hline Mean arterial blood pressure (Mean \pm SD) & $<50$ Years old & Before drug injection & & & \\
\hline & & After drug injection & $88.81 \pm 10.60$ & $89.86 \pm 8.02$ & 0.54 \\
\hline & $>50$ Years old & Before drug injection & $99.53 \pm 9.96$ & $102.32 \pm 8.99$ & 0.06 \\
\hline & & After drug injection & $96.14 \pm 9.38$ & $89.68 \pm 8.10$ & 0.001 \\
\hline \multirow[t]{4}{*}{ Heart rate $($ Mean $\pm S D)$} & \multirow[t]{2}{*}{$<50$ Years old } & Before drug injection & $90.40 \pm 12.01$ & $87.36 \pm 7.80$ & 0.10 \\
\hline & & After drug injection & $93.73 \pm 11.04$ & $96.51 \pm 11.67$ & 0.19 \\
\hline & \multirow[t]{2}{*}{$>50$ Years old } & Before drug injection & $88.77 \pm 11.41$ & $88.06 \pm 8.83$ & 0.65 \\
\hline & & After drug injection & $92.20 \pm 11.27$ & $96.14 \pm 10.34$ & 0.022 \\
\hline
\end{tabular}

Note: *Student's $t$-test.

administration, but after the drug administration, this difference was statistically significant $(\mathrm{P}=0.001)$ (Table 4).

In this study, the relation between possible drug side effects in different groups based on age and sex were investigated. At baseline, there were no significant differences regarding heart rate and MAP, between different subgroups of two groups. As shown in Table 5 , the heart rate and MAP were significantly different between two groups in patients over 50 years old ( $\mathrm{P}=0.001$ and $\mathrm{P}=0.022$, respectively) and males ( $\mathrm{P}=0.001$ and $\mathrm{P}=0.006$, respectively) but no statistically significant differences were observed in patients younger than 50 years old and females $(\mathrm{P}=0.19$ and $\mathrm{P}=0.54$, respectively) (Table 6).

\section{Discussion}

To our best of knowledge, this study is the first work evaluating the efficacy and adverse effects of low dose of Hyoscine, compared to its usual dose during ERCP. The ERCP method is the best non-surgical intervention for benign and malignant biliary duct diseases. ${ }^{19,20}$ The absence of peristalsis during ERCP is necessary for cannulation of the bile ducts and pancreas, especially for sphincterotomy. ${ }^{21}$ Also, the absence of peristalsis during the procedure will lead to a better view of the anatomic details of the Vater ampulla and the intraduodenal part of the common biliary duct. Over the past years, both glucagon and Hyoscine have been used to remove duodenal peristalsis. Pharmacological studies have shown that Hyoscine has anticholinergic 
Table 6 The Frequency of Side Effects of Drug by Sex

\begin{tabular}{|c|c|c|c|c|c|}
\hline \multicolumn{3}{|l|}{ Variables } & \multirow{2}{*}{$\begin{array}{l}\begin{array}{l}\text { Group I } \\
\text { (5 } \mathbf{~ m g )}\end{array} \\
97.28 \pm 10.45\end{array}$} & \multirow{2}{*}{$\begin{array}{l}\begin{array}{l}\text { Group } 2 \\
(10 \mathrm{mg})\end{array} \\
99.58 \pm 9.59\end{array}$} & \multirow{2}{*}{$\begin{array}{l}\text { P-value* } \\
0.21\end{array}$} \\
\hline \multirow{4}{*}{$\begin{array}{l}\text { Mean arterial blood pressure (Mean } \pm \\
\text { SD) }\end{array}$} & \multirow[t]{2}{*}{ Male } & Before drug Injection & & & \\
\hline & & After drug Injection & $94.64 \pm 9.36$ & $89.35 \pm 7.85$ & 0.001 \\
\hline & \multirow[t]{2}{*}{ Female } & Before drug Injection & $96.15 \pm 12.37$ & $97.30 \pm 8.02$ & 0.66 \\
\hline & & After drug Injection & $92.74 \pm 11.20$ & $90.03 \pm 8.18$ & 0.08 \\
\hline \multirow[t]{4}{*}{ Heart rate (Mean $\pm S D)$} & \multirow[t]{2}{*}{ Male } & Before drug Injection & $87.96 \pm 11.12$ & $88.76 \pm 8.46$ & 0.65 \\
\hline & & After drug Injection & $91.04 \pm 10.24$ & $96.15 \pm 9.71$ & 0.006 \\
\hline & \multirow[t]{2}{*}{ Female } & Before drug Injection & $90.57 \pm 11.95$ & $88.96 \pm 8.20$ & 0.15 \\
\hline & & After drug Injection & $94.24 \pm 11.82$ & $96.43 \pm 11.76$ & 0.24 \\
\hline
\end{tabular}

Note: *Student's t-test.

properties with a high affinity for muscarinic receptors on gastrointestinal smooth muscle cells. In addition to its peripheral anticholinergic activity, it also has a gradual and longlasting sedative effect on the central nervous system. Due to the anticholinergic effects of this drug, its possible side effects may include dry mouth, dryness and itching of the skin, skin lesions in cases of drug allergy, drowsiness, forgetfulness, mydriasis, cycloplegia, dry eye and cardiovascular complications (primary bradycardia due to muscarinic receptors blockage and partial tachycardia). It also binds to nicotine receptors and causes a ganglion-blocking effect that can cause cardiovascular complications such as cardiac arrhythmias and blood pressure fluctuations. Sometimes Hyoscine helps to improve autonomic balance in patients with heart failure. ${ }^{22-25}$

In this study, three variables were studied to evaluate the efficacy of the drug: the time interval between injection of the drug and cessation of peristalsis, duration of antispasmodic effect, and the time needed to increase heart rate. The results of this study showed that there was no statistically significant difference between the mean duration of time required for the reduction of peristalsis in the two groups. However, the mean time required to mitigate peristalsis in the first group (5 mg) was shorter than in the second group (10 mg). Regarding the duration of the antispasmodic effect, the results also showed that there was no significant difference between different doses $(5$ and $10 \mathrm{mg})$. In terms of the time needed to increase the heart rate, this study also showed that both doses (5 and $10 \mathrm{mg}$ ) did not differ.

In this study, for assessing the adverse effects of the drug, arrhythmia, heart rate, and MAP were evaluated. The results showed that there was no significant difference between the two groups in terms of the frequency of arrhythmia (before and after drug administration). In the first group (5 mg Hyoscine injection), no arrhythmia was reported after first and second doses., but in the second group (10 mg Hyoscine injection), three cases (2.1\%) had arrhythmia ( 2 cases of supraventricular and one ventricular) after second dose of drug. A clinical trial on 36 patients undergoing peripheral angiography in aortoiliac region showed that injection of $20 \mathrm{mg}$ dose of Hyoscine was associated with an increase in the heart rate of subjects, and two patients had procedural ST depression compared with none in the control group. However, there was no statistical difference between the two groups. ${ }^{27}$

Regarding the heart rate and MAP, the results showed that there was a statistically significant difference between these groups after drug administration. The average of MAP was lower in the second group (10 mg Hyoscine). In other words, hypotension was more common in the second group after drug administration. The mean heart rate was also higher in the second group (10 mg Hyoscine) than the first group, which means tachycardia occurred more frequently in the second group, in comparison with the first one. In the prospective study of Christensen et al in 2004, 1177 ERCP cases were recorded over two years. The results of this study showed that in $15.9 \%$ of the participants, complications of the procedure (in a one-month duration after surgery) occurred. Pancreatitis (3.8\%), hemorrhage $(0.9 \%)$, perforation (1.1\%), cholangitis $(5 \%)$, and cardiorespiratory complications were reported in $2.3 \%$ of the study participants. The 
results of this study indicate that factors such as dilated bile duct, stenting, and injection of more than $40 \mathrm{mg}$ of Hyoscine are risk factors for post-ERCP complications. ${ }^{28}$ In line with the results of the mentioned study, our results showed that side effects (tachycardia and hypotension) were more common in the patients receiving higher doses of Hyoscine.

Fisher et al aimed to investigate the effects of ERCP in the two groups of individuals over 65 years of age and those under 65 years old. Its results indicate that significant hemodynamic changes occurred in both groups during ERCP. These include increases in heart rate, systolic and diastolic blood pressure, as well as MAP. Findings of the study showed that the mean heart rate was significantly higher in the patients over 65 than in the patients under 65 and it was reported that the higher frequency of receiving Hyoscine in people under 65 years old leads to the increased mean of the heart rate. The results of our study also showed that the mean heart rate in the second group (10 mg Hyoscine) was higher than the first group $(5 \mathrm{mg}$ Hyoscine), which was in line with the results of the mentioned study. ${ }^{29}$

As the majority of the patients undergoing ERCP are old age, we should use the lowest effective dose of the drug. A study was conducted by Glomsaker et al to determine the predictive factors for possible complications of ERCP. In this study, 2808 cases of ERCP were performed, and complications occurred in 327 procedures (11.6\%). Among these complications, cholangitis (3.6\%), pancreatitis (3.1\%), bleeding (2.4\%), perforation (0.9\%) and cardiopulmonary complications $(1.1 \%)$ were noted. In this study, age has been identified as a risk factor for ERCP-induced complications so that with increasing the age (especially in people over 90 years of age), the risk of ERCP-related complications also increases. ${ }^{30,31}$ Our study also showed that the MAP and heart rate in both groups were significantly different in those over 50 years old compared to those under 50 years, which was in line with the results of this study.

Some trials have tried to use oral GI spasmolytic agents in order to decrease systemic side effect of Hyoscine-N-butyl bromide. In a study by Karahan et $\mathrm{al}^{26}$ the effect of oral Otilonium bromide (a GI spasmolytic agent with minimal systemic distribution) usage during ERCP on duodenal motility, the tolerability (by patients) and the difficulty (by the endoscopist) of the procedure was evaluated. Otilonium bromide is a muscarinic agonist and also a calcium channel blocker with low risk of side effects. The results showed that the mean duodenal motility score was significantly lower in the study group, compared to control group. Also, the patient satisfaction rate was higher in the study group. The authors concluded that using this agent before ERCP can decrease the duodenal motility and ease the procedure. More randomized studies that compare oral versus intravenous spasmolytic agents during ERCP are needed.

\section{Conclusion}

Low dose of Hyoscine-N-butyl bromide is effective and safe for prevention of peristalsis during ERCP and side effects such as alteration in blood pressure and heart rate are much fewer especially in men and elderly patients.

\section{Data Sharing Statement}

The datasets used and/or analyzed during the current study will be de-identified and are available from the corresponding author on reasonable request up to 2 years after publication.

\section{Disclosure}

The authors report no conflicts of interest in this work.

\section{References}

1. Moutinho-Ribeiro P, Peixoto A, Macedo G. Endoscopic retrograde cholangiopancreatography and endoscopic ultrasound: to be one traveler in converging roads. GE Portuguese J Gastroenterol. 2018;25 (3):138-145. doi:10.1159/000481537

2. Adler DG, Baron TH, Davila RE, et al. ASGE guideline: the role of ERCP in diseases of the biliary tract and the pancreas. Gastrointest Endosc. 2005;62(1):1-8. doi:10.1016/j.gie.2005.04.015

3. Early DS, Ben-Menachem T, Decker GA, et al. Appropriate use of GI endoscopy. Gastrointest Endosc. 2012;75(6):1127-1131. doi:10.10 16/j.gie.2012.01.011

4. Chang F, Guo W, Liao T, Lee S. A randomized study comparing glucagon and hyoscine N-butyl bromide before endoscopic retrograde cholangiopancreatography. Scand J Gastroenterol. 1995;30 (3):283-286. doi:10.3109/00365529509093278

5. Froehlich JM, Daenzer M, von Weymarn C, Erturk SM, Zollikofer CL, Patak MA. Aperistaltic effect of hyoscine N-butylbromide versus glucagon on the small bowel assessed by magnetic resonance imaging. Eur Radiol. 2009;19(6):1387-1393. doi:10.1007/s00330-008-1293-2

6. Gutzeit A, Binkert CA, Koh D-M, et al. Evaluation of the anti-peristaltic effect of glucagon and hyoscine on the small bowel: comparison of intravenous and intramuscular drug administration. Eur Radiol. 2012;22(6):1186-1194. doi:10.1007/s00330-011-2366-1

7. Lahoti S, Catalano MF, Geenen JE, Hogan WJ. A prospective, double-blind trial of L-hyoscyamine versus glucagon for the inhibition of small intestinal motility during ERCP. Gastrointest Endosc. 1997;46 (2):139-142. doi:10.1016/S0016-5107(97)70061-0

8. Hannigan B, Axon A, Avery S, Thompson R. Buscopan or glucagon for endoscopic cannulation of ampulla of vater? J R Soc Med. 1982;75 (1):21.

9. Hashimoto T, Adachi K, Ishimura N, et al. Safety and efficacy of glucagon as a premedication for upper gastrointestinal endoscopy - a comparative study with butyl scopolamine bromide. Aliment Pharmacol Ther. 2002;16(1):111-118. doi:10.1046/j.1365-2036.20 02.01148.x 
10. Tytgat GN. Hyoscine butylbromide. Drugs. 2007;67(9):1343-1357. doi:10.2165/00003495-200767090-00007

11. Chen G-L, Hsu W-H. Hyoscine-N-Butyl-bromide-induced hypotension and myocardial ischemia. Case Rep Critical Care. 2013;2013:1-3. doi:10.1155/2013/414856

12. Smith D, O'Connell P. Cardiac dysrhythmias during oral surgery. Comparison of hyoscine and droperidol premedication. Anaesthesia. 1986;41(7):745-748. doi:10.1111/j.1365-2044.1986.tb12845.x

13. Giesen H. Cardiac side-effects of oesophago-gastro-duodenoscopy in relation to premedication (author's transl). Deutsche medizinische Wochenschrift (1946). 1978;103(39):1517-1520. doi:10.1055/ s-0028-1129293

14. Ozaslan E, Karakelle N, Ozaslan NG. Hyoscine-N-butylbromide induced ventricular tachycardia during ERCP. J Anaesthesiol Clin Pharmacol. 2014;30(1):118. doi:10.4103/0970-9185.125733

15. Johnston S, McKenna A, Tham T. Silent myocardial ischaemia during endoscopic retrograde cholangiopancreatography. Endoscopy. 2003;35(12):1039-1042. doi:10.1055/s-2003-44597

16. Han SJ, Lee TH, Kang BI, et al. Efficacy and safety of therapeutic endoscopic retrograde cholangiopancreatography in the elderly over 80 years. Dig Dis Sci. 2016;61(7):2094-2101. doi:10.1007/s10620016-4064-y

17. Ramsay M, Savege T, Simpson B, Goodwin R. Controlled sedation with alphaxalone-alphadolone. Br Med J. 1974;2(5920):656-659. doi:10.1136/bmj.2.5920.656

18. Dinc B, Gunduz UR, Bas B, et al. The efficacy of intravenous hyoscine-N-butylbromide during colonoscopy: a prospective, randomized, double-blind, placebo-controlled study. Acta Gastroenterol Belg. 2016;79(2):179-185.

19. Maple JT, Ben-Menachem T, Anderson MA, et al. The role of endoscopy in the evaluation of suspected choledocholithiasis. Gastrointest Endosc. 2010;71(1):1-9. doi:10.1016/j.gie.2009.09.041

20. Baron TH, Mallery JS, Hirota WK, et al. The role of endoscopy in the evaluation and treatment of patients with pancreaticobiliary malignancy. Gastrointest Endosc. 2003;58(5):643-649. doi:10.1016/ S0016-5107(03)01994-1

21. Reddy DN, Nabi Z, Lakhtakia S. How to improve cannulation rates during endoscopic retrograde cholangiopancreatography. Gastroenterology. 2017;152(6):1275-1279. doi:10.1053/j.gastro.2017.03.041
22. Kristoffersen MB, JP Clausen. Bradycardia and hypotension during cyclopropane anaesthesia caused by hyoscine as premedication. BJA. 1967;39(7):578-584. doi:10.1093/bja/39.7.578

23. Casadei B, Pipilis A, Sessa F, Conway J, Sleight P. Low doses of scopolamine increase cardiac vagal tone in the acute phase of myocardial infarction. Circulation. 1993;88(2):353-357. doi:10.1161/01. CIR.88.2.353

24. La Rovere MT, Mortara A, Pantaleo P, Maestri R, Cobelli F, Tavazzi L. Scopolamine improves autonomic balance in advanced congestive heart failure. Circulation. 1994;90(2):838-843. doi:10.1161/01.CIR.90.2.838

25. Venkatesh G, Fallen EL, Kamath MV, Connolly S, Yusuf S. Double blind placebo controlled trial of short term transdermal scopolamine on heart rate variability in patients with chronic heart failure. Heart. 1996;76(2):137-143. doi:10.1136/hrt.76.2.137

26. Ö K, Sevinç B, Okuş A, Ay S, Aksoy N. Otilonium bromide as spasmolytic during endoscopic retrograde cholangiopancreatography. Surg Endosc. 2015;29(8):2266-2269. doi:10.1007/s00464-014-3939-2

27. Maher R, Philips-Hughes J, Banning A, Boardman P. The frequency and significance of silent myocardial ischemia due to hyoscine butylbromide use in peripheral angiography. Cardiovasc Intervent Radiol. 1999;22(5):369-374. doi:10.1007/s002709900409

28. Christensen M, Matzen P, Schulze S, Rosenberg J. Complications of ERCP: a prospective study. Gastrointest Endosc. 2004;60 (5):721-731. doi:10.1016/S0016-5107(04)02169-8

29. Fisher L, Fisher A, Thomson A. Cardiopulmonary complications of ERCP in older patients. Gastrointest Endosc. 2006;63(7):948-955. doi:10.1016/j.gie.2005.09.020

30. Glomsaker T, Hoff G, Kvaløy J, et al. Patterns and predictive factors of complications after endoscopic retrograde cholangiopancreatography. Br J Surg. 2013;100(3):373-380. doi:10.1002/bjs.8992

31. Kounis N, Zavras G, Papadaki P, et al. Electrocardiographic changes in elderly patients during endoscopic retrograde cholangiopancreatography. Can J Gastroenterol Hepatol. 2003;17(9):539-544.
Clinical Pharmacology: Advances and Applications is an international, peer-reviewed, open access journal publishing original research, reports, reviews and commentaries on all areas of drug experience in humans. The manuscript management system is completely online and includes a very quick and fair peer-review system, which is all easy to use. Visit http://www.dovepress.com/testimonials.php to read real quotes from published authors. 